\title{
Pictorial essay on a case of giant retroperitoneal liposarcoma
}

\author{
Muhamed Tajudeen, ${ }^{1}$ Souradeep Dutta $\quad(1),{ }^{1}$ Srinivas Bheemanathi, ${ }^{2}$ \\ Amaranathan Anandhi (1) ${ }^{1}$
}

${ }^{1}$ Surgery, Jawaharlal Institute of Postgraduate Medical Education and Research, Puducherry,

Pondicherry, India

${ }^{2}$ Pathology, Jawaharlal Institute of Post Graduate Medical Education, Pondicherry, Pondicherry, India

\section{Correspondence to} Dr Amaranathan Anandhi; anandhiramesh76@yahoo.in

Accepted 20 October 2020

\section{DESCRIPTION}

A 47-year-old man presented with problems of progressive abdominal distension for 3 months, associated with dull aching abdominal pain, increasing with food intake. He gave a 1-month history of shortness of breath on exertion and swelling of the lower limbs. On examination, he was pale and malnourished. Abdominal examination showed a variegated large mass occupying the left hypochondriac, lumbar, iliac, umbilical and hypogastric regions with prominent veins due to inferior vena cava compression over the abdominal wall (figure 1A,B). Haemoglobin was low $(7.2 \mathrm{gm} /$ dL) with normal renal and liver function tests except for a low albumin status.

Contrast enhanced CT (CECT) revealed large soft-tissue masses involving almost the whole of abdomen with varying densities consisting of lipomatous elements, calcifications and heterogeneously enhancing lobulated solid lesions abutting the anterior abdominal wall (figure $1 \mathrm{C}-\mathrm{E}$ ). There was displacement of bowel loops and encasements of both the kidneys, superior mesenteric artery (SMA) and inferior mesenteric artery (IMA)

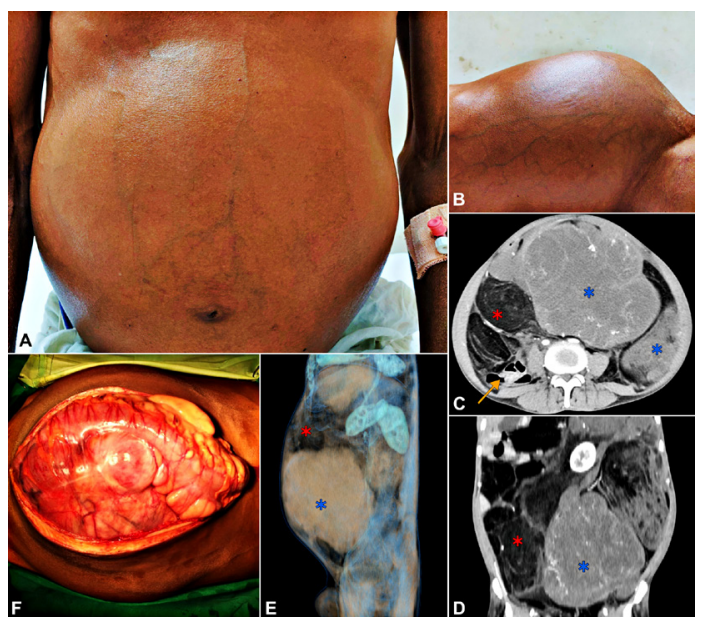

Figure $1 \quad(A, B)$ Clinical photographs of the patient showing distended abdomen with prominent veins. (C, $D$, E) The contrast enhanced CT. (C) Axial section. (D) Coronal section. (E) Three-dimensional reconstruction with a sagittal view from the left side. Blue stars indicate the solid areas of the tumour (HU: 25-35). Red stars indicate the lipomatous portions (HU: -60 to -85 ). Yellow arrow in (D) shows the displaced bowel loops to the right. (F) Intraoperative photograph of the tumour after laparotomy.

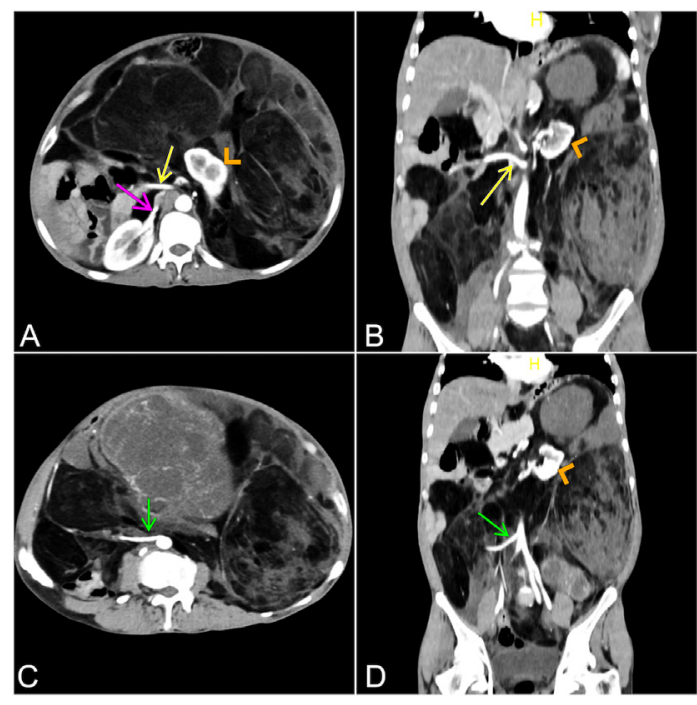

Figure 2 Sections from CT showing involvement of the bilateral kidneys and the superior mesenteric artery (SMA) and inferior mesenteric artery (IMA). (A) Axial section at the plane of origin of SMA. Yellow arrow shows the SMA going through the lipomatous mass to the gut in the right side. Pink arrow shows lipomatous mass around the region of right renal hilum. Yellow arrowhead shows the displaced left kidney in the tumour mass. (B) Coronal section showing origins of SMA through the tumour mass (yellow arrow). Yellow arrowhead shows the displaced left kidney in the tumour mass. (C) Axial section at the plane of origin of IMA. Green arrow shows the IMA going through the tumour mass. (D) Coronal section showing origins of IMA through the tumour mass (green arrow). Yellow arrowhead shows the displaced left kidney in the tumour mass.

(figure 2). There was no evidence of lymph node involvement or distant metastasis.

Institutional multidisciplinary tumour board decided against trying a neoadjuvant therapy due to lack of enough (levels I, II) evidence, combined with the patient's poor performance status and deteriorating symptoms. Because of the tumour board decision and confirmed CECT report as liposarcoma, we have decided to go ahead with surgery without preoperative biopsy. Intraoperatively, large irregular glistening multiple swellings on the left side, with varying consistencies, were noted arising from the retroperitoneum displacing the entire abdominal viscera to the right (figure $1 \mathrm{~F}$ ). The tumour was seen encasing bilateral kidneys, root of mesentery and mesocolon of left colon. En-bloc resection was not possible due to the involvement 


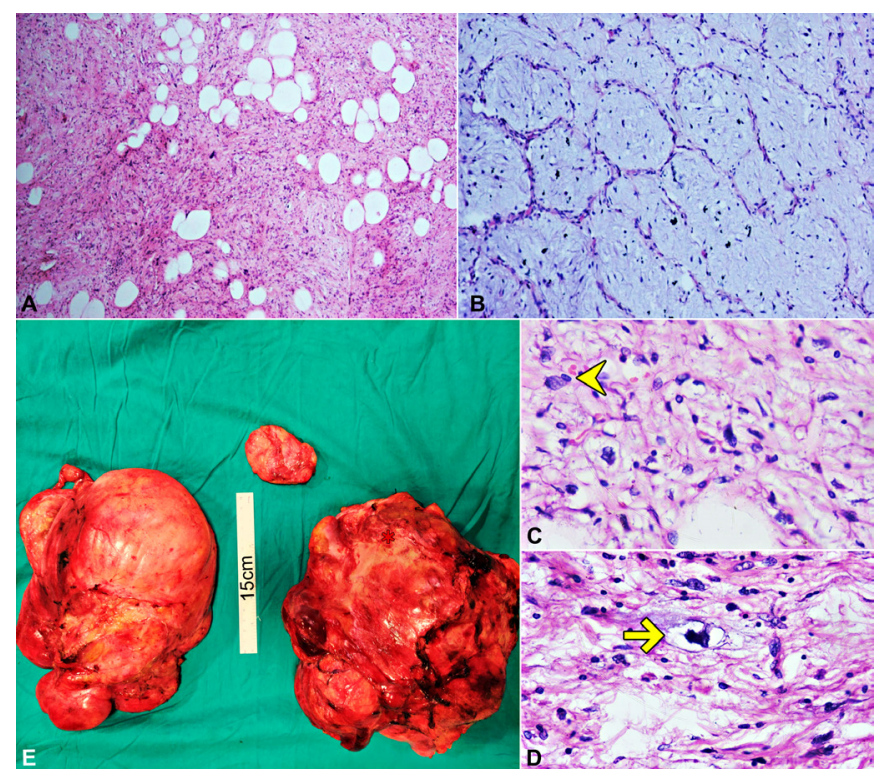

Figure 3 (A-D) Histopathological slides. (A) Microscopy show lobules of varying sized adipocytes admixed with increased stromal cellularity (H\&E $\times 100)$. (B) Focal areas show myxoid background admixed with chicken wire capillaries $(H \& E \times 200)$. (C) Atypical stromal cells (yellow arrowhead) (H\&E $\times 400)$. (D) Atypical stromal cells admixed with scattered lipoblasts which show scalloped nucleus (yellow arrow) (H\&E $\times 200$ ). (E) Gross specimens following resection-shows three lobulated masses (with both lipomatous and solid elements) of size: $28 \times 22 \times 14$ $\mathrm{cm}, 22 \times 17 \times 15 \mathrm{~cm}$, and $8 \times 4.5 \times 2 \mathrm{~cm}$.

of both kidneys, SMA and IMA. Debulking of the large tumour was done to palliate the symptoms. An anatomopathological study on the surgical specimen showed tumour composed of fat lobules of varying sizes, with cells arranged in myxoid background with chicken wire capillaries with the diagnosis of a welldifferentiated liposarcoma (grade 1) (figure 3). He underwent adjuvant chemotherapy with 6 cycles of doxorubicin $(80 \mathrm{mg} /$ cycle), followed by a cross-sectional imaging for response evaluation. He had a progressive disease following the chemotherapy and is currently under palliative care 1 year after the surgery.

The incidence of soft-tissue sarcomas (STS) is $<1 \%$ of all malignancies. Retroperitoneum is the site of involvement in $15 \%$ of the cases of STS. And almost $40 \%$ of retroperitoneal sarcomas are liposarcomas (RPLS). ${ }^{1}$ The histological variants are well-differentiated, dedifferentiated, pleomorphic, myxoid and round cell liposarcomas. ${ }^{2}$ The tumours tend to be asymptomatic initially followed by a late presentation when the tumour has outgrown the retroperitoneal space. The most common symptom is abdominal mass or fullness, which is unilateral and progressively increasing. ${ }^{3}$ At a later stage of the disease, patients can present with gastrointestinal or urinary or neurological complaints owing to the compression or invasion of adjacent structures. ${ }^{2}$ CECT remains the investigation of choice and allows us to identify the location, extension and the proximity to the neurovascular structures. Image-guided core-needle biopsy via retroperitoneal approach is the gold standard for diagnosis. ${ }^{4}$ Under microscopy, hyperchromatic single cells with broad cellular septae and multivacuolated lipoblasts are often diagnostic. $^{5}$ A complete surgical resection is the standard of care in RPLS although radiotherapy and chemotherapy have been described. RPLS are labelled unresectable when there is extensive major visceral arterial and vital organs involvement. ${ }^{3}$ Although preoperative radiotherapy has been shown to decrease

\section{Patient's perspective}

I was having rapid increase in the size of my abdomen for last few months, so much so that I was having difficulty in breathing while sleeping. I suffered with abdominal pain which was really disturbing and increased every time I was having my food. I also lost my appetite and there was swelling of my feet too. I had consulted the hospital's surgery clinic and was admitted for further evaluation. I underwent a few scans and after evaluation I was told I have a tumour inside my abdomen, which requires surgery. Doctors also explained me preoperatively that removing the entire tumour might be difficult sometimes if my vital organs are involved. I was taken up for the operation. After operation I was shifted to intensive care unit and was observed there for one day. I could see some dressings over the tummy. I had to bear with difficult news that some part of the tumour was left over inside my abdomen as both of my kidneys were involved along with some major vessels. It was devastating. I had some pain in my abdomen for the first 2 days, which then resolved slowly. I felt lighter and size of the abdomen became smaller. But I was told the tumour would probably again increase in size. I was asked not to take food for a day. Slowly I recovered from the surgery. I had to consult the medical oncology department, who advised me with some chemotherapy regimen. I was discharged on 10th day following surgery.

I will have to thank the entire team for their compassionate care and for riding with me in the most difficult part of my life.

\section{Learning points}

- Liposarcomas are the most common retroperitoneal sarcomas (40\%) with a wide variety of histological types: welldifferentiated, dedifferentiated, pleomorphic, myxoid and round cell.

- Contrast enhanced CT is the radiological investigation of choice and most often shows masses with varying densities (both lipomatous and solid components).

- A debulking treatment can be considered in exceptional cases as emergency treatment in patients with huge unresectable masses and severe compression complications. Though recurrence would be inevitable, there can be a minor survival benefit or improvement in quality of life as well differentiated liposarcomas grow slowly and rarely metastasise. The patient in this report is alive during the time of writing the report, 1 year from the debulking surgery.

the local recurrence in a few studies, their role is not definite so far. ${ }^{6}$ Prognosis varies with the histological subtypes, tumour grade and completeness of the surgical resection.

\section{Twitter Souradeep Dutta @souradeep}

Contributors The idea for the article by MT. SD and MT performed the literature search, AA and SB wrote the article, and AA is the guarantor.

Funding The authors have not declared a specific grant for this research from any funding agency in the public, commercial or not-for-profit sectors.

Competing interests None declared.

Patient consent for publication Obtained.

Provenance and peer review Not commissioned; externally peer reviewed.

ORCID iDs

Souradeep Dutta http://orcid.org/0000-0002-1600-3439 
3 van Houdt WJ, Zaidi S, Messiou C, et al. Treatment of retroperitoneal sarcoma: current standards and new developments. Curr Opin Oncol 2017;29:260-7.

4 Messiou C, Morosi C. Imaging in retroperitoneal soft tissue sarcoma. J Surg Oncol 2018:117:25-32.

\section{REFERENCES}

1 Windham TC, Pisters PWT. Retroperitoneal sarcomas. Cancer Control 2005;12:36-43.

2 Argadjendra M, Napitupulu R, Yudadi R, et al. Kidney sparing giant retroperitoneal liposarcoma: case report and literature review. Int J Surg Case Rep 2019;56:70-3.

5 Renne SL, Iwenofu OH. Pathology of retroperitoneal sarcomas: a brief review. J Surg Oncol 2018:117:12-24.

6 Haas RL, Baldini EH, Chung PW, et al. Radiation therapy in retroperitoneal sarcoma management. J Surg Oncol 2018;117:93-8.

Copyright 2020 BMJ Publishing Group. All rights reserved. For permission to reuse any of this content visit https://www.bmj.com/company/products-services/rights-and-licensing/permissions/

BMJ Case Report Fellows may re-use this article for personal use and teaching without any further permission.

Become a Fellow of BMJ Case Reports today and you can:

- Submit as many cases as you like

- Enjoy fast sympathetic peer review and rapid publication of accepted articles

- Access all the published articles

Re-use any of the published material for personal use and teaching without further permission

\section{Customer Service}

If you have any further queries about your subscription, please contact our customer services team on +44 (0) 2071111105 or via email at support@bmj.com.

Visit casereports.bmj.com for more articles like this and to become a Fellow 